\title{
AUTORIDAD/SUBVERSIÓN EN EL PLUTO DE ARISTÓFANES: UN NUEVO DIOS A LA CABEZA
}

\author{
Roberto Morales Harley*
}

\begin{abstract}
RESUMEN
Sobre la base de la consideración de los mitos griegos como textos culturales, este trabajo analiza el Pluto de Aristófanes como un tratamiento paródico y carnavalesco de las luchas por la sucesión entre los dioses. A partir de los indicios textuales relacionados con la lexía $\kappa € \varphi \alpha \lambda \eta ́$ (cabeza), se establece una inversión cómica del eje semiótico autoridad/subversión.
\end{abstract}

Palabras clave: Aristófanes, Pluto, cabeza, texto cultural, autoridad/subversión.

\begin{abstract}
On the basis of the consideration of Greek myths as cultural texts, this paper analyses Aristophanes' Plutus as a parodic and carnivalesque treatment of the fights for succession among the gods. From the textual marks related with the $\kappa \varepsilon \varphi \alpha \lambda \eta$ (head) lexia, it establishes a comic inversion of the authority/subversion semiotic axis. Key Words: Aristophanes, Plutus, head, cultural text, authority/subversion.
\end{abstract}

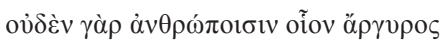

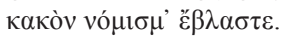
Ninguna costumbre mala para los hombres brotó de la tierra; solamente el dinero. (Sófocles. Antígona, 295-296)

\section{Introducción}

Pluto, comedia presentada en 388 a.C., es la última que Aristófanes pone en escena a su nombre (Cócalo y Eolosicón aparecieron a nombre de su hijo). Constituye probablemente una reelaboración de una versión anterior, que dataría de 408 a.C. Tanto por su fecha de composición como por su estructura y su temática, forma un grupo con La asamblea de las mujeres, puesto que ambas obras prefiguran en varios aspectos lo que será la comedia posterior. La obra se centra en el dios Pluto, quien, privado de su vista, reparte las riquezas injustamente. Crémilo acude al oráculo de Apolo para saber si es preferible educar a su hijo como alguien bueno o malo, y recibe la respuesta de invitar a su casa al primero que pase por el santuario. Se trata de Pluto, a quien Crémilo, junto con su esclavo Carión, ayuda a restituir en la posición divina que le corresponde. Tras someterse a dos consagraciones y a una purificación ritual, el dios recupera su vista, y, en una serie de escenas finales, revierte las situaciones de los personajes según sus méritos: el hombre justo y el sicofanta, 
la vieja y el joven, Hermes y el sacerdote. La comedia finaliza con un komos festivo, mediante el cual se celebra el triunfo de Pluto.

La condición de obra de transición atribuida a Pluto ha resultado en que sea una de las comedias menos estudiadas y valoradas de la producción de Aristófanes. A modo de ejemplo, Rodríguez y Rodríguez (Aristófanes, 2004: 207-208) sostienen que faltan en esta obra algunos de los elementos más característicos de la comedia aristofánica: un héroe cómico (ni Pluto ni Crémilo cumplen esta función), una mayor participación del coro de labradores (no hay parábasis), un agón entre protagonista y antagonista (Penia es un personaje añadido).

Una revisión de algunos de los trabajos más representativos revela una tendencia general hacia tres enfoques teóricos: el análisis de la obra como perteneciente al género literario cómico, la determinación de los aspectos que producen la risa, y la fijación de relaciones entre el texto literario y el contexto histórico.

(1) El género literario. Para Arnott (1972: 65), si la Comedia Antigua termina con Las ranas de Aristófanes y la Comedia Nueva empieza con El díscolo de Menandro, en consecuencia, La asamblea de las mujeres (presentada en 392-391) y Pluto (presentada en 388) serían los dos únicos ejemplos completos que se han conservado de Comedia Media. Por el contrario, Dick (1963: 265) resalta la presencia en esta obra de elementos característicos de las distintas etapas de la comedia; y García (1996: 191 y 197) incluso afirma que el Pluto de Aristófanes llega a influir, no solo en la comedia, en $E l$ misántropo de Menandro, sino también en el diálogo, en El misántropo de Luciano.

(2) La comicidad. Según Gil (1993: 28 y 30), la comicidad del Pluto residiría en una mezcla del componente intelectual (por el juego de palabras que se establece al hablar de salvar a Pluto de la ceguera que le causó Zeus salvador) y del social (por la ironía con que se refiere a las instituciones democráticas). Por su parte, Sardón (1996: 198-201) señala la presencia, en la obra de Aristófanes, de elementos carnavalescos, relacionados con el realismo grotesco, en Las nubes, Las ranas y Lisistrata; no menciona el Pluto.

(3) El contexto histórico. Lasso (1972: 11) propone que la comedia aristofánica une los contrarios (idealidad dionisíaca y realidad política) y transforma la realidad en algo fantástico (como utopía) o en algo grotesco (como sátira). Varios autores coinciden en el aspecto fantástico e irónico: Konstan y Dillon (1981: 388) mencionan este tratamiento en dos tópicos, la distribución desigual de la riqueza y la escasez frente a la abundancia; McGlew (1997: 51-52) destaca la inadecuación entre la progresión dramática y la secuencia lógica, porque vence el argumento más débil; y Zumbrunnen (2006: 331-332) observa la introducción de un nuevo modelo de justicia económica y social, basado en el reconocimiento cómico de la igualdad en la diferencia.

Adicionalmente, cabe destacar algunos trabajos cuyo enfoque y resultados influyeron en la elaboración de este estudio. Dos son del mismo autor: en uno (Douglas, 1989: 196-197), se propone que la transformación de Carión, reflejo de una evolución en la concepción griega de esclavitud, está marcada por su comparación con personajes de la mitología (el Cíclope y Circe cuando es rebelde, Hermes cuando es tranquilo); en el otro (Douglas, 1990: 241-242), se arguye que, sobre la base de una consideración de la pobreza de la población rural griega, la comedia se establece como un mecanismo de control social. Hay otros dos artículos: el primero, de Groton (1990: 17), recuerda las funciones de la utilería y los disfraces: etiquetadora (e. g., las coronas de Crémilo y Carión los etiquetan como suplicantes), simbólica (e. g., la corona de Carión simboliza la protección de Apolo), y causativa (e. g., la corona de Carión causa la amenaza de Crémilo). El segundo, de Paradiso (1987: 266-267), plantea que la obra evidencia la estructura de un rito de paso, necesario para ingresar tanto en casa de Crémilo como en el templo de Atenea.

En este trabajo, se siguen algunos de estos planteamientos, pero desde otra perspectiva: la lectura de los indicios en la semiótica textual. Así se propone que, además de la parodia cómica del contexto histórico, existe una parodia de los 
textos culturales míticos que se aprecia en las luchas por la sucesión del poder entre los dioses. Como afirma Howatson (1991: 660), "Crémilo busca identificar a Pluto con Zeus". A esto se podría añadir que Pluto se convierte, gracias a la metáfora, en el nuevo poder a la cabeza de los dioses. Para demostrar esta hipótesis, se empleará el enfoque de la Sociocrítica, especialmente en los planteamientos de Cros (2002), apoyado en algunas consideraciones terminológicas extraídas de Beristáin (1997).

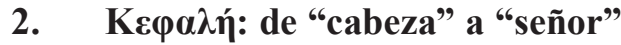

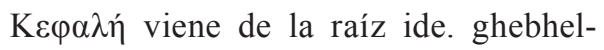
(Watkins, 2000: 28), que significa gablete, especie de estructura triangular que se encuentra en la parte más alta de ciertos edificios. El proceso es el siguiente: ghebhel$>$ *khephal (desonorización) > *kephal(disimilación). Desde la raíz se puede apreciar el sentido de superioridad, de una cosa que está por encima de otra.

En griego (Chantraîne, 1968: 522),

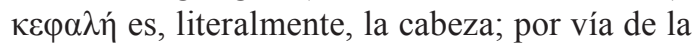
sinécdoque, la persona; y, gracias a la metáfora, la totalidad, el acabamiento, la coronación. El sentido de primacía está presente, mayormente, en los compuestos derivados del sufijo - aotc. Así,

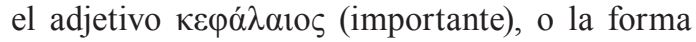
neutra sustantivada $\kappa \varepsilon \varphi \alpha ́ \lambda \alpha$ lov (cabeza, región de la cabeza, punto principal, esencial, capital, suma total; en griego tardío incluso significa "capítulo", voz española que, a su vez, deriva del latín capitulum y, por tanto, pertenece a la familia léxica de caput). Igualmente, conserva este sentido el verbo denominativo $\kappa \varepsilon \varphi \alpha \lambda \alpha$ ı́ $\omega$ (dar lo esencial, resumir, dar el total).

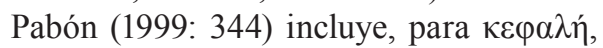
los siguientes sentidos: (1) cabeza; (2) persona, hombre; (3) parte superior, dominante, principal; (4) fin, extremidad; (5) fuente, origen; (6) piedra angular; (7) jefe, señor. El último valor es, precisamente, el que sirve de base para esta lectura: por analogía con el cuerpo físico, donde la cabeza ocupa el lugar privilegiado, el sentido se extiende al cuerpo social, donde el jefe sobresale. En el pensamiento griego, la cabeza estaba asociada con la principalía y, por consiguiente, con la autoridad. Entre los dioses, asociar a un dios con la cabeza es ponerlo en relación con la autoridad (e. g., el mito de Atenea, que nace de la cabeza de Zeus).

En términos simbólicos, Chevalier (2007: 221) entiende la cabeza como "el ardor del principio activo", el cual incluye "la autoridad de gobernar, de ordenar y esclarecer". Así, dos atributos significativos de quien se sitúa a la cabeza del cuerpo social son la facultad de gobernar sobre otros (autoridad) y la necesidad de manifestar, aunque sea se forma indirecta, este orden de cosas (revelación).

Con respecto al poder entre los dioses, el mito principal es el de las luchas de sucesión: Urano sucumbe ante Cronos; Cronos, ante Zeus. Este se establece como el último dios de la línea de sucesión al controlar a todos sus oponentes: los Titanes, Tifón, y la misma Atenea. Así surge el orden, tales son la cosmogonía y la cosmología. Pero, ¿qué sucede cuando se cuestiona el orden establecido? La comedia, del mismo modo que parodia la realidad histórica de la ciudad, puede parodiar su tradición mítica. En ambos casos, se trata de un discurso oficial (los gobernantes, los dioses) que dictan las normas a las cuales debe someterse el común de la población. Mediante la extensión de la analogía, ya no de lo físico a lo social, sino de lo social a lo religioso, Pluto opera en los dos niveles: el histórico y el mítico.

El primero de estos niveles ha sido abordado por varios autores; el segundo se puede analizar a partir de una sencilla hipótesis de trabajo: los mitos son textos culturales. El concepto proviene de la teoría sociocrítica y Cros lo define de la siguiente manera:

Un fragmento de intertexto de un determinado
tipo, que interviene según modos específicos de
funcionamiento en la geología de la escritura.
Se trata de un esquema narrativo de naturaleza
doxológica en la medida en que corresponde a
un modelo infinitamente retransmitido, el cual,
como consecuencia, se presenta como un bien
colectivo cuyas marcas de identificación originales
han desaparecido (Cros, 2002: 189).

El mito, igualmente, posee un carácter doxológico. Si este se entiende, siguiendo a 
García (2004: 11ss), como un "relato", con un "carácter dramático y ejemplar" y con un "valor paradigmático" como fenómeno social, que se remonta a los orígenes; con esto en mente, es posible postular la inscripción del mito griego en la literatura griega, más que como un tema, como un componente esencial, perteneciente a la tradición, a la memoria colectiva, al conjunto de saberes del pueblo, y, particularmente, como un elemento cuyo principio, al remontarse a un tiempo más allá del tiempo, es imposible de determinar. Las obras literarias pueden tener autores, los mitos no.

Otras características del texto cultural también lo ponen en relación con el mito:

(1) "No posee verdadera vida autónoma" (Cros, 2002: 189), puesto que solo se manifiesta de forma fragmentaria y en una semiótica subyacente. Del mismo modo, el mito griego aparece solo parcialmente en las obras literarias griegas, porque se supone su conocimiento por parte de la colectividad.

(2) "Es enigma en sí y marca en el texto un enigma" (Cros, 2002: 189), por lo que su desciframiento conduce hacia la significación. El enigma es un motivo privilegiado en el mito griego, especialmente en los oráculos, donde el lenguaje, en tanto posee un doble nivel de significación, requiere de un proceso de decodificación. Por lo demás, junto con la cosmogonía y la escatología, la etiología es uno de los temas centrales de la mitología (García, 2004: 19).

(3) "Cuanto más débiles son los indicios, mayor es el 'placer del texto', más elevado el grado de adhesión a lo colectivo y la fusión entre el destinador y el destinatario en el seno del mismo sujeto" (Cros, 2002: 190). La cultura, como mecanismo de cohesión social, se puede valer de la literatura para crear consciencia de unidad. Por ello, la épica griega puede iniciar in medias res, y la tragedia griega puede desarrollar la acción en el marco del ciclo épico. Si la literatura griega puede ser la elaboración de verosímiles ficciones, los mitos griegos constituyen la verdadera historia del pueblo. Ahora bien, para nosotros, ajenos a la cultura griega, son enigmas que invitan a su propio desciframiento.
Dos momentos son básicos para la interpretación. El primer paso consiste en la identificación de indicios en la semiótica textual. Esto conlleva un primer problema: las connotaciones presentan distintos grados. Cros (2002: 170) propone una organización provisional de los semas que funcionan como pares de opuestos, para su clasificación en los niveles correspondientes. Siguiendo este modelo, se pueden establecer los siguientes niveles de significación y pares de semas opuestos en el Pluto:

Nivel 0 (denotación)
Riqueza/pobreza
Visión/ceguera
Nivel 1 (organización social)
Autoridad/subversión
Cordura/locura
Nivel 2 (proyección ideológica)
Revelación/ocultación
Justicia/injusticia

Se es rico o pobre según un orden prestablecido, el cual se puede poner en entredicho mediante la dialéctica de autoridad/ subversión. Esta se manifiesta indirectamente en un juego de revelación/ocultación. Del mismo modo, se es vidente o ciego de acuerdo con una predisposición, pero esta oposición se puede emplear para referirse al cordura/locura de una persona, o incluso a la justicia/injusticia de un pueblo.

El segundo paso es determinar la relación de estos indicios con los textos culturales o los intertextos ordinarios que se inscriben en la obra. Pluto es una comedia y, en consecuencia, desarrolla las acciones bajas de personajes de dicha condición. Uno de los principales mecanismos de comicidad lo ofrece la inscripción, en un género con estas características, de elementos más propios de un género elevado, como la tragedia $\mathrm{y}$, sobre todo, la épica. Los textos culturales que aparecen en el Pluto son los mitos griegos asociados con el poder; el intertexto ordinario, la Odisea.

A estos pasos habría que añadir un tercero: analizar los mecanismos que posibilitan 
la relación entre los indicios, los textos culturales y los intertextos ordinarios. En el Pluto, son, esencialmente, dos: la parodia de los mitos y de la épica, y la inversión carnavalesca de los ejes semióticos autoridad/subversión y revelación/ ocultación. La parodia (Beristáin, 1997: 391) es una "imitación burlesca de una obra, un estilo, un género, un tema, tratados antes con seriedad", que se da en casos en que el discurso del narrador es divergente con el de los personajes.

Por su parte, el carnaval (Bernstein, citado por Beristáin, 1997: 81) "traviste, corona, descorona, invierte los rasgos e intercambia los roles, da sentido al sinsentido y convierte los roles y convierte en un sinsentido el sentido". Valga la aclaración de que no se pretende, con este trabajo, un análisis completo de la obra desde la teoría del carnaval, sino, simplemente, una lectura relacionada con la idea básica de inversión carnavalesca, particularmente relacionada con la corona, símbolo de poder que se ubica en la cabeza, y que resulta fundamental para entender la parodia mítica.

\section{Los indicios en la onomástica}

La principal oposición que se establece es entre riqueza y pobreza. De acuerdo con

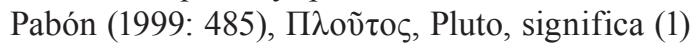
riqueza, fortuna, abundancia, tesoro, ganancia; (2) felicidad, bendición; (3) poder. El primer grupo de palabras remite al campo semántico de los bienes materiales, cuya posesión se asocia con un principio rector externo; el segundo se vincula, más bien, con la condición emocional positiva, derivada de la situación favorable; y el tercero se relaciona, directamente, con el eje semiótico autoridad/subversión. La riqueza no solo produce efectos en el plano individual, como la felicidad, sino que también determina la fijación o la alteración del orden establecido, por medio del poder.

Al respecto, resulta interesante la proximidad, en términos etimológicos, entre el dios Pluto, la riqueza personificada, y el dios $\Pi \lambda$ ov́ $\omega$ v, Plutón, el rico, epíteto con el cual se suele nombrar a Hades. También a él, aunque con distintas formas de ambigüedad, le corresponden los significados de los tres campos semánticos: la riqueza, tanto los frutos como los metales, puesto que ambos, al encontrarse escondidos en las profundidades de la tierra, se relacionan con el eje semiótico revelación/ocultación; la felicidad, para quienes gozan de estos bienes en vida, pero que se torna tristeza en el mundo de los muertos, dado que todo pierde su valor; y el poder, el cual, en el texto cultural de la repartición cósmica, le asigna a Hades la región inferior de la esfera, de igual extensión que el Olimpo y la Tierra juntos, si se considera la medición del yunque que cae de un extremo al otro, durante nueve días en cada dirección.

Como contraparte de Pluto aparece Пєvía, Penia, que, como señala Pabón (1999: 467), significa pobreza, indigencia, penuria. Igualmente, a falta de recursos, decaen la estabilidad emocional y la preminencia social. En consecuencia, se establecen las oposiciones entre ricos y pobres, entre felices y tristes, y entre poderosos y débiles; no obstante, en virtud de la ambigüedad del mito, así como de lo carnavalesco como medio para lograr la comicidad, es posible todo tipo de inversiones.

Los otros dos nombres importantes son el del amo y el del esclavo. Crémilo deriva del sustantivo en plural $\chi \rho \eta ́ \mu \alpha \tau \alpha$, el cual, según Pabón (1999: 646), significa: (1) haber, bienes, riqueza, propiedad, fortuna, hacienda; (2) mercancías, géneros, dinero; (3) fondos, erario, capital, tesoro. El primer grupo de palabras está vinculado al campo semántico de las posesiones materiales, y el segundo apunta hacia los intercambios comerciales que posibilitan tales posesiones; ambos sugieren, por tanto, la relación entre el amo y el dios Pluto. El tercero no solo remite a la acumulación, sino a la primacía que de ella deriva ("capital" viene de caput).

A su vez, Carión deriva del sustantivo

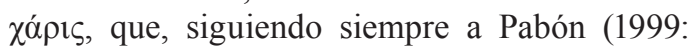
639), abarca, entre otros, los siguientes sentidos: (1) gracia, atractivo, encanto, belleza, hermosura, donaire, garbo, elegancia; (2) goce, placer, gusto, satisfacción, contento, deleite; (3) benevolencia, bondad, liberalidad, generosidad, indulgencia; (4) favor, merced, beneficio, utilidad, servicio; (5) salario, gratificación, remuneración, 
recompensa. El primer grupo se refiere al aspecto físico, y lo bello en oposición a lo feo ya representa una inversión de la caracterización tradicional del esclavo; el segundo, asociado a lo sexual, se encuentra más próximo al personaje, al tiempo que a la noción de carnaval; el tercero es más propio del amo pero el cuarto lo es del esclavo, por lo que se vuelve sobre el eje semiótico autoridad/subversión; y el quinto retoma el tema del dinero, que es, desde el título, el motivo central de la obra.

Por medio de la onomástica, por tanto, se puede agrupar a Crémilo y Carión, quienes participan de una relación bastante cercana, junto a Pluto, en el bando de la riqueza. Del otro lado, se encontraría Penia, con quien quedaría asociado, por vía de la inversión de la autoridad y de la jerarquía, Zeus.

\section{Los indicios en las lexías}

Para el análisis de la obra se sigue la edición griega de Hall and Geldart (1907), así como la traducción española de Rodríguez y

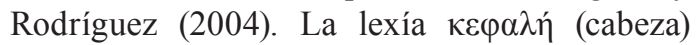
aparece en once ocasiones en el texto. Las primeras cuatro se encuentran en el agón entre Crémilo y Penia, todas en boca de aquel.

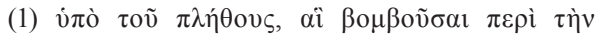

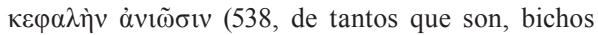
que zumbando en torno a tu cabeza te dan lata)

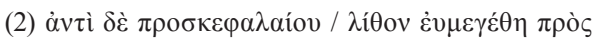
$\tau \tilde{n} \kappa \varepsilon \varphi \alpha \lambda \tilde{n}$ (542-543, y en vez de almohada, una gran piedra junto a la cabeza)

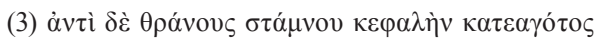
(545, y en vez de un escabel, la cabeza de un cántaro roto)

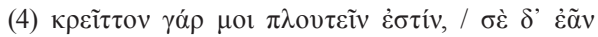

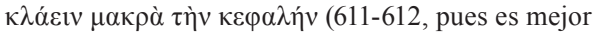
que yo sea rico y que tú te hieras la cabeza)

En (1) se mencionan las criaturas que rodean a Penia; en (2) y (3), los recursos que emplea para apoyarse. Esta caracterización negativa de la pobreza se remata con la afirmación de (4): derrotar al enemigo con palabras es el equivalente físico de asestarle un golpe en la cabeza.

A continuación, hay seis formas del término en el diálogo en que Carión narra a la mujer de Crémilo lo ocurrido en el templo de Asclepio. (5), (7), (8), (9) y (10) son palabras de Carión; (6) es una intervención de la mujer de Crémilo.

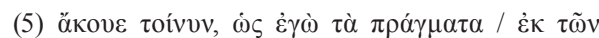

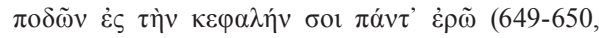
óyeme pues, que yo los sucesos te los voy a contar de pies a cabeza)

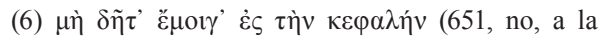
cabeza no)

(7) $\dot{\alpha} \lambda \lambda \dot{\alpha} \mu \varepsilon / \dot{\alpha} \theta \dot{\alpha} \rho \eta \varsigma \chi v ́ \tau \rho \alpha \tau 1 \zeta \dot{\varepsilon} \xi \dot{\varepsilon} \pi \lambda \eta \tau \tau \varepsilon \kappa \varepsilon 1 \mu \varepsilon \dot{v} \eta \eta /$

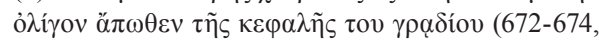
sino que me volvía loco por una marmita llena de gachas que estaba un poco más allá de la cabeza de una viejita)

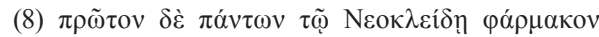

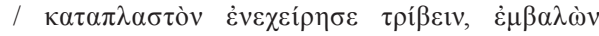

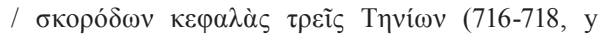
primero para Neoclides encargó machacar un emplasto triturado, echándole tres cabezas de ajos de Tenos)

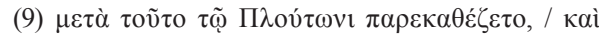

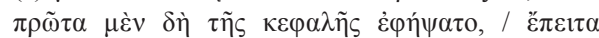

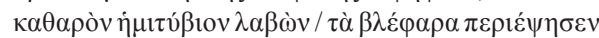
(727-730, tras esto, el dios se sentó junto a Pluto; y, lo primero, le acarició la cabeza y, cogiendo un paño bien limpio, le enjugó los párpados)

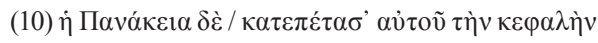

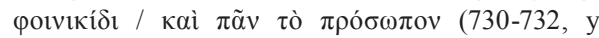
Panacea cubrió su cabeza y todo el rostro con un paño púrpura)

(5) es uno de los casos más llamativos: se trata de una locución para expresar que algo se contará de forma completa. Sin embargo,

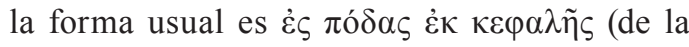
cabeza a los pies, e. g. Il. 23, 169; cfr. Bailly, 2000: 1085). Aquí se invierte con una finalidad cómica. (6) es la contestación a esta propuesta: el final en la cabeza ha sido interpretado como un golpe, algo no infrecuente para los esclavos, 
con lo cual se explota aún más el juego de palabras anterior.

(7) anticipa ya el final de la comedia: la marmita en la cabeza de una vieja, como símbolo del nuevo orden. (8), (9) y (10) se refieren a la importancia de la cabeza en el rito de purificación: respectivamente, al fármaco y a las dos etapas del proceso curativo, el contacto y la ocultación.

La última mención de la lexía, ofrecida con el número (11), ocupa un lugar muy significativo en la escena final y retoma el tema de (7): se ha establecido un nuevo orden, hay un nuevo dios a la cabeza. Crémilo habla a la vieja.

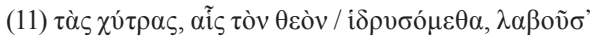
$\dot{\varepsilon} \pi \grave{i} \tau \tilde{\eta} \varsigma \kappa \varepsilon \varphi \alpha \lambda \tilde{\eta} \varsigma$ $\varphi \varepsilon ́ \rho \varepsilon / \sigma \varepsilon \mu \nu \tilde{\varsigma} \varsigma$ (1197-1199, las marmitas con las que vamos a consagrar al dios, cógelas y llévalas solemnemente en la cabeza)

A estas once apariciones de $\kappa \varepsilon \varphi \alpha \lambda \eta ́$ habría que sumar otras lexías que guardan una estrecha relación con la noción de cabeza $y$ con el eje semiótico autoridad/subversión. Estas se observan en tres ámbitos: la estructura dramática (prólogo, agón, desenlace), la utilería (coronas, harapos) y la inversión de las parejas de personajes (justo y sicofanta, joven y vieja, sacerdote y Hermes).

Desde el inicio, en la intervención de Carión que hace las veces de prólogo, la semiótica textual evidencia una serie de indicios que determinan el desarrollo del argumento. El esclavo afirma la dificultad de servir a un amo $\pi \alpha \rho \alpha \varphi \rho \operatorname{covov} v \tau o \varsigma(2$, que está loco), con lo que ya se enmarca la inversión: el esclavo cuerdo se sitúa, en términos racionales, por encima del amo loco, con lo cual se da vuelta al eje semiótico autoridad/subversión; $\mathrm{y}$, a su vez, el amo loco, como personaje característico del carnaval, es el más inclinado a decir la verdad, aunque no siempre de manera comprensible, con lo cual se invierte el eje semiótico revelación/ocultación.

El esclavo menciona a $\Lambda$ o $\xi i ́ a$ (8, Loxias), el oblicuo, epíteto de Apolo que hace referencia a la oscuridad de las respuestas del oráculo. El dios se caracteriza a partir de dos de sus funciones tradicionales: la adivinación y la medicina. En relación con la primera, la inversión consiste en que, en vez de aclarar el porvenir, lo oscurece con el velo del discurso; con respecto a la segunda, la inversión implica que no solo no ha sido capaz de curar al amo, sino que lo ha empeorado con la enfermedad de la locura. En

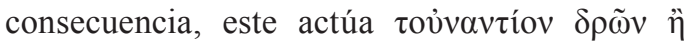

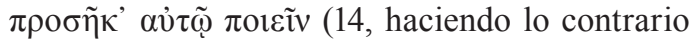

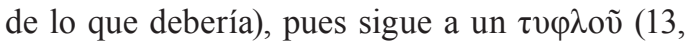
ciego). Usualmente, el vidente sirve de guía al ciego, pero aquí ocurre lo contario.

La ceguera se puede entender en una triple vertiente: como un problema físico, el de la imposibilidad de percepción sensorial de los ojos; como un problema mental, el de la incapacidad de percepción cognitiva del raciocinio; y como una complejidad esencial al proceso de comprensión textual. A medida que se avanza en el texto, los indicios permiten ver de qué se trata, es decir, comprender su sentido.

Al final del parlamento, las palabras del esclavo proporcionan otro indicio: $\sigma \tau \varepsilon \dot{\varepsilon} \varphi \alpha v o v(21$, la corona). Esta es el atributo característico de los suplicantes que visitan el oráculo de Delfos; en este sentido, la obra inicia por la ocultación, para moverse luego hacia la revelación, que, eso sí, es solo parcial, y el proceso se refleja en los usos de la corona. También la corona, ubicada en la cabeza, es el atributo de los vencedores en los juegos Olímpicos, que, consagrados a Zeus, remiten, más bien, a este otro dios, situado en el centro del panteón griego, como representante del orden establecido. De esta forma, el texto parte de la subversión en la dirección de una autoridad alternativa, no la de Zeus sino la de Pluto. Sobre la función de la corona, escribe Groton:

Thus the motifs of wreaths and rags serve a number of purposes in the Plutus: they strengthen the links between verbal humor and visual humor; they keep the spectators guessing about what twists of theme to expect next; they help, by their very frequency of appearance, to unify the play's various scenes; and they parallel in their own development the growth and success of that fantastic new society in which Wealth will reign supreme, having exchanged his blindness for sight, his sadness for joy, and his rags for a wreath. (Groton, 1990: 22). 


\begin{abstract}
Entonces, los motivos de coronas y harapos sirven para varios propósitos en el Pluto: fortalecen los vínculos entre el humor verbal y el humor visual; mantienen a los espectadores adivinando los giros del tema por esperar; ayudan, con su sola frecuencia de aparición, a unificar las varias escenas de la obra; y trazan un paralelo, con su propio desarrollo, del crecimiento y el éxito de la nueva sociedad fantástica en la cual la Riqueza reinará soberana, habiendo cambiado su ceguera por la vista, su tristeza por la alegría, y sus harapos por una corona. (Traducción del autor).
\end{abstract}

Esta dimensión de la autoridad también constituye uno de los principales indicios de la semiótica textual. Interrogado por Crémilo sobre la causa de su ceguera, Pluto explica que esta le fue producida por Zeus $\alpha \nu \theta \rho \omega ́ \pi$ orৎ $\varphi \theta$ ovãv (87, por envidia a los hombres), ya que este no quería que aquel favoreciera a los

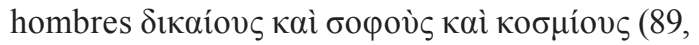
justos, sabios y honorables). Irónicamente, Zeus, el salvador, perjudica a Pluto. Por una parte, el odio hacia los hombres y sus benefactores evoca el texto cultural de Prometeo, quien roba el fuego divino para los hombres, y los faculta así para las actividades intelectuales; por otra, la indiferencia, ejemplificada en la ceguera, ante los premios o castigos dispensados a los hombres sugiere, más bien, el texto cultural religioso, específicamente, el de la vida ultramundana, donde no por ser buenos los mortales reciben recompensas, sino por mero capricho divino. Con respecto a esta actitud de Zeus, apunta Dover:

The assumption that Zeus deliberately makes things difficult and unpleasant for mankind is not uncommon; it is a translation of the observation that life is hard from empirical into theological language. (Dover, 1972: n. 202).

La asunción de que Zeus deliberadamente hace las cosas difíciles y desagradables para la humanidad no es infrecuente; es una traslación de la observación de que la vida es difícil desde el lenguaje empírico hacia el teológico. (Traducción del autor).

El tema de la ceguera continúa a través del texto en relación con la inversión. Crémilo, al prometer al Pluto que le devolverá la vista, asegura que le conseguirá una vista ỏ $v^{\prime} \tau \varepsilon \rho$ v

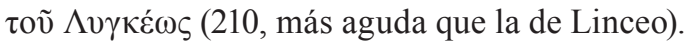
La referencia es al texto cultural de la expedición de los Argonautas, en la cual participó este personaje, caracterizado, principalmente, por su buena visión. Así, se trata de condiciones radicalmente opuestas: el tránsito de una ausencia total de visión a la mejor visión que se pueda conseguir.

También se asocia con la ceguera el intertexto ordinario de la Odisea que se inscribe en la obra. La parodia se efectúa en una de las intervenciones del Coro, y Carión imita las acciones más bajas, en correspondencia con el género cómico. En la primera estrofa, la inversión es completa: el papel protagónico no recae sobre Odiseo o sus compañeros, encarnados por el Coro, sino sobre el Cíclope, representado por Carión; y el cíclope no es un personaje bárbaro, sino que ofrece muestras de dominar los elementos culturales propios del festejo, el baile y el canto. También la mención de los puercos, animal con connotaciones sexuales, pone en evidencia el aspecto carnavalesco de episodio.

\section{Kapíwv}

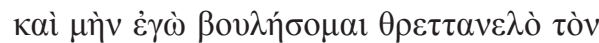

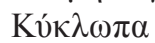

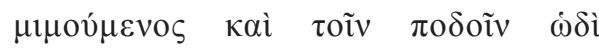
$\pi \alpha \rho \varepsilon v \sigma \alpha \lambda \varepsilon v ́ \omega v$

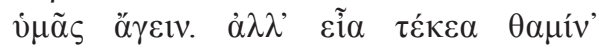
$\dot{\varepsilon} \pi \alpha \nu \alpha \beta$ о $\nu \tau \varepsilon \varsigma \varsigma$

$\beta \lambda \eta \chi \omega ́ \mu \varepsilon v o i ́ ~ \tau \varepsilon \pi \rho o \beta \alpha \tau i ́ \omega v$

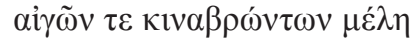

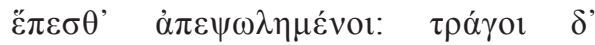
$\alpha \kappa \rho \alpha \tau \varepsilon \tilde{\imath} \sigma \theta \varepsilon(290-295)$

Carión

Pues yo voy a querer / -taralalá- al Cíclope Imitando y así / gritando con mis pies

Dirigir vuestro baile. / Ea. Hijos, gritando Y gritando y cantando canciones

De ovejas y fétidas cabras

Venid descapullados: / vais a comer cual puercos.

La primera antistrofa relata el acontecimiento de la estaca con que se ciega 
al Cíclope. Así como Pluto podía ver y perdió dicha facultad a causa de Zeus, el Cíclope se ve privado del don por Odiseo y sus compañeros. Asimismo, cabe destacar el paralelismo entre los motivos: si Odiseo, como mortal, necesitaba cegar al Cíclope para salvar su vida y la de sus compañeros; del mismo modo, Zeus, como dios, necesitaba cegar a Pluto para salvar su condición y la de los otros dioses. Los inmortales no temen a la muerte, pero sí al abandono. Y solo mediante una distribución injusta de la riqueza se consigue que los sacerdotes dispongan de bienes para ofrendar a los dioses corruptos. En este sentido, la crítica política se extiende al ámbito religioso, y, por medio del ideologema de la barbarie, trasladado del Cíclope a Zeus, se censura la indiferencia moral del juez. Adicionalmente, la mención de la borrachera retoma el componente dionisíaco y carnavalesco. El eje semiótico principal es el de autoridad/subversión.

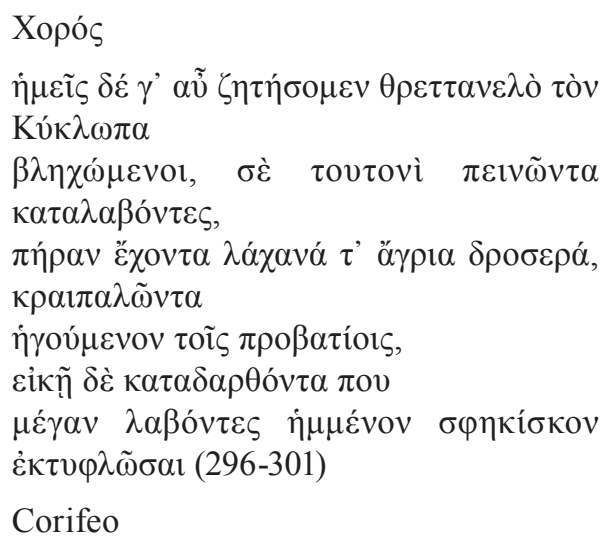

Nosotros buscaremos / -taralalá- al Cíclope

Balando; y alcanzándote / a ti, sucio, que llevas

Una alforja con hierbas / silvestres y borracho

Vas cual pastor de tu rebaño,

Cogiéndote al azar dormido

Con una gran estaca / ígnea te cegaremos.

En la segunda estrofa, la parodia es de Circe. Aquí la ceguera no se refiere a la imposibilidad de percepción visual, sino al carácter oculto del mensaje. También presenta la imitación de acciones bajas, así como el elemento carnavalesco sugerido por la connotación sexual de los puercos. Pero, adicionalmente, señala el texto cultural de la mitología que rodea a Apolo: por un lado, la medicina, en tanto el fármaco griego puede ser, según la medida en la que sea administrado, tanto un veneno como un remedio; y, por otro, la adivinación, puesto que Circe posee el don en razón de su ascendencia solar. Ambas facetas se conjugan en la locura y en la ceguera. Sin embargo, en este caso el eje semiótico principal es el de revelación/ocultación.

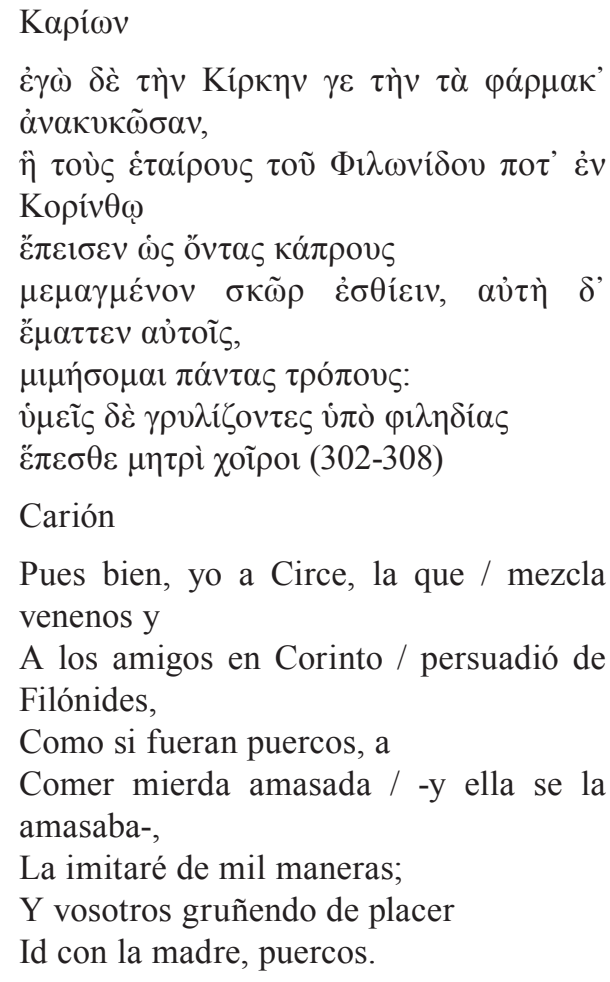

Pues bien, yo a Circe, la que / mezcla venenos y

A los amigos en Corinto / persuadió de Filónides,

Como si fueran puercos, a

Comer mierda amasada / -y ella se la amasaba-,

La imitaré de mil maneras;

$\mathrm{Y}$ vosotros gruñendo de placer

Id con la madre, puercos.

La segunda antistrofa retoma el componente sexual, tan característico de lo carnavalesco. Ahora la inversión remite la lexía $\kappa \varepsilon \varphi \alpha \lambda \eta ́$ en relación con la autoridad. No es de la cabeza que cuelgan a Odiseo sino de sus genitales, y ya no es el héroe quien se encuentra a la cabeza de la acción, sino la hechicera. Si el Cíclope cumplía con los requisitos para formar parte del conglomerado de la otredad por su barbarie, Circe calza como mujer. De 
este modo, el esclavo, imitando al Cíclope y a la hechicera, se corona a la cabeza del movimiento subversivo que acabará por sustituir a Zeus por Pluto en el poder.

Xopós

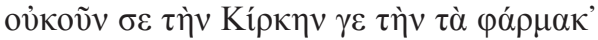
$\dot{\alpha} v \alpha \kappa v \kappa \tilde{\sigma} \sigma \alpha \nu$

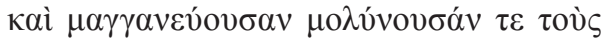

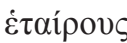

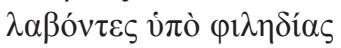

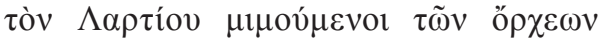
$\kappa \rho \varepsilon \mu \tilde{\omega} \mu \varepsilon v$,

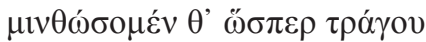

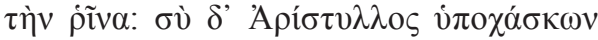
$\dot{\varepsilon} \rho \varepsilon \tilde{i} \varsigma$,

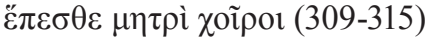

Corifeo

Pues a ti, esa Circe / que los venenos mezcla,

Que practica artes mágicas / y ensucia a mis amigos,

Con placer agarrándote

Como Odiseo, de los / huevos te colgaremos

$\mathrm{Y}$ enmendaremos tu nariz

De cabrón; y dirás, Aristilo:

Id con la madre, puercos.

Que se trata de una inversión carnavalesca queda claro en el uso de lexías como $\sigma \kappa \omega \mu \mu \alpha ́ \tau \omega v$ (316, bromas) y عĩ $\delta o \varsigma ~(317$, juego), que plantean lo cómico como opuesto a lo serio. Pero también el hecho de que este no constituye el sentido último se puede deducir del epodo: el esclavo va $\lambda \alpha \dot{\alpha} \theta \rho \alpha$ (318, a escondidas). Por consiguiente, toda esta subversión se somete a una ocultación, y no es sino en la revelación donde se puede apreciar la autoridad alternativa.

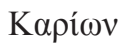

$\dot{\alpha} \lambda \lambda \lambda^{\prime} \quad \varepsilon \tilde{i} \alpha \quad v \tilde{v} v \quad \tau \tilde{\omega} v \quad \sigma \kappa \omega \mu \mu \alpha ́ \tau \omega v$ $\dot{\alpha} \pi \alpha \lambda \lambda \alpha \gamma \varepsilon \dot{\varepsilon} \nu \varepsilon \varepsilon \zeta \ddot{\eta} \delta \eta$

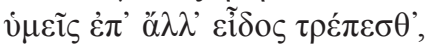

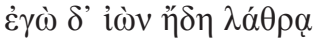

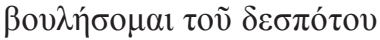

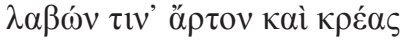

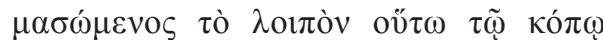

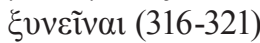

Carión

Pero, ea, dejaos / ya de esas bromas vuestras,

Pasando ya ahora a otro juego.

Yo voy a escondidas, ahora,

Del amo, a entrar y a procurar,

Cogiendo algo de pan y carne,

Mientras me lo manduco, / hacer ya mi trabajo.

El agón cómico se plantea en términos de la oposición riqueza/pobreza, y consigue, a través de la inversión paródica propia del carnaval, no solo el efecto cómico, sino también una marcada ambigüedad. En la argumentación que enfrenta a Crémilo y a Penia, las palabras, a la vez que subversivas, son veladas, por lo que, en el mismo núcleo cómico de la obra, se mezclan los dos ejes semióticos principales: autoridad/subversión y revelación/ocultación. Esta sería una posible explicación del desfase entre consecuencias lógicas y consecuencias dramáticas que ha visto la crítica (cfr. McGlew, 1997: 51-52).

La argumentación se puede sintetizar en los siguientes puntos:

Crémilo (a) opina que ahora los malos son ricos y los buenos pobres, esto es una $\mu \alpha v i ́ \alpha v$ (501, locura) y lo justo sería que la situación estuviera al revés.

Penia (a) contesta que si Pluto ve de nuevo y reparte por igual, ningún hombre querrá trabajar, y esta es la verdadera $\pi \alpha \rho \alpha \pi \alpha i \varepsilon \omega v$ (508, locura).

Crémilo (b) asegura que los esclavos harán las labores penosas.

Penia (b) establece un argumento práctico, al afirmar que como todos serán ricos, nadie querrá dedicarse a vender esclavos, por lo que serán los amos quienes deban esclavizarse al trabajo, y nadie podrá disfrutar su riqueza, porque tampoco habrá nadie que quiera dedicarse a fabricar objetos lujosos; en cambio, ella sí puede ofrecer estos beneficios.

Crémilo (c) cree que alguien que no posee las condiciones básicas para la vida, como alimento, vivienda y vestimentas, no puede 
procurar bienes a otros; y las ropas de Penia son ¡́́́ко (540, harapos).

Penia (c) responde que esa descripción corresponde a la vida del mendigo, que vive sin tener nada, pero bien distinta es la vida del pobre, quien vive sin que le sobre nada, pero también sin que le falte nada.

Crémilo (d) admite, irónicamente, la felicidad de tal suerte.

Penia (d) ataca el argumento cómico, mediante el cual solo se puede $\sigma \kappa \omega ́ \pi \tau \varepsilon ı v ~(557$, burlar) y $\kappa \omega \mu \omega \delta \varepsilon \tilde{i v}$ (557, ridiculizar), y añade un argumento moral, al establecer que los hombres pobres son mejores, en cuerpo y espíritu, que los ricos; por ejemplo, si los políticos son pobres, son justos en sus decisiones, pero, al enriquecer, se tornan injustos.

Crémilo (e) duda de su posición y pregunta por qué, si la pobreza es mejor que la riqueza, Zeus tiene a Pluto.

Penia (e) afirma que Zeus es pobre, por eso en los juegos Olímpicos $\sigma \tau \varepsilon \varphi \alpha v \omega ́ \sigma \alpha \varsigma$ (585, corona) a los vencedores con olivo y no con oro.

La postura de Penia parece la más sólida: a partir de la locura (a), establece las ventajas de la pobreza en dos niveles, el práctico $(b, c)$ y el moral (d), y concluye su defensa con un elogio del orden establecido, que coloca a Zeus a la cabeza de los dioses (e). Por su parte, el punto de vista de Crémilo se tambalea: igualmente, desde la locura, pero como inversión (a), defiende el orden social del esclavo (b) y el amo (c), aunque le parezca atractiva la posición contraria, $y$, justamente por ello, es capaz de reírse de sí mismo (d) y de dudar (e). Esta problematización constituye, en efecto, la esencia de la comedia, en tanto posibilita la inversión cómica propia del carnaval.

La curación de Pluto se lleva a cabo en el templo de Asclepio. Esta divinidad se inscribe también el texto cultural de la mitología en torno a Apolo, específicamente en relación con la medicina. Sin embargo, este hijo de Apolo no deja de manifestar una estrecha cercanía con respecto al eje semiótico autoridad/subversión, porque, gracias a sus inigualables atributos curativos, que aprendiera del centauro Quirón, consiguió, mediante el empleo de la sangre de la Gorgona que le proporcionó Atenea, revertir el proceso natural de la vida, trayendo de regreso a los muertos. Quizás constituya esta la mayor clase de subversión que pueden emprender los mortales: intentar asemejarse a los dioses en su inmortalidad. El resultado de esta arriesgada empresa fue, como en el caso de Prometeo, el castigo de Zeus. Asclepio fue fulminado por el rayo, atributo del poder en su manifestación de fuerza, y se convirtió en una constelación.

Este es, precisamente, el motivo del miedo que recubre a los intentos de subversión. Al querer Carión narrar a la esposa de Crémilo lo

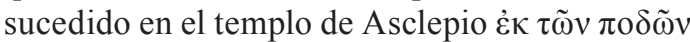

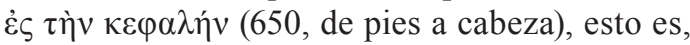
de principio a fin, ella, asustada responde que

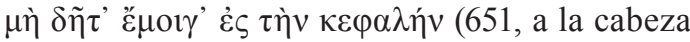
no), como cualquier persona de condición inferior, porque los golpes a la cabeza, a la autoridad son peligrosos. Posteriormente, en la narración del esclavo se encuentran tres indicios significativos: los $\varphi \theta 0 \tilde{\varsigma}$ (677, pasteles), de harina blanca, miel y queso, que preparadas especialmente para el ritual, son comidas en un ambiente de glotonería, característico de la inversión carnavalesca; el $\tau \rho \imath \beta \omega v i ́ o v ~(715$, sayo), hecho harapos, cuyos huecos, dejan al esclavo ver el ritual que debería estarle velado, por lo que se inscriben en el eje semiótico revelación/ ocultación; y los $\beta \lambda \varepsilon ́ \varphi \alpha \rho \alpha$ (736, párpados), donde se aplica el remedio a la ceguera, que es curada en Pluto, para que pueda repartir con justicia, pero que es infligida en un político, para deje de ocasionar injusticias, nuevamente, se trata de una inversión, pero ahora en relación con el eje semiótico autoridad/subversión.

Pluto, habiendo recobrado su visión, sale del templo de Asclepio con una comitiva que, en medio de gritos y bailes, parodia las procesiones rituales. Los que antes eran injustos $\mathrm{y}$ ricos ha sido derrotados, pero quienes eran justos y pobres ahora marchan $\dot{\varepsilon} \sigma \tau \varepsilon \varphi \alpha \nu \omega \mu \dot{\varepsilon} v o 1$ (757, coronados). El propio Pluto avanza a la

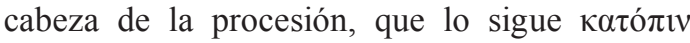
(757, detrás), y se debe someter a una primera consagración, en casa de Crémilo. Este ritual se efectúa por medio del rociado de golosinas sobre la cabeza del dios, de la misma forma que se procedía ante el ingreso de una nueva esposa o de un nuevo esclavo al dominio doméstico. 
El propio término $\kappa \alpha \tau \alpha \chi v ́ \sigma \mu \alpha \tau \alpha$, derivado del

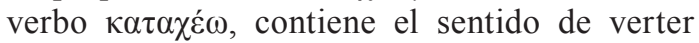

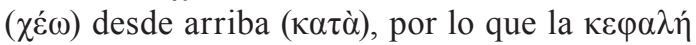
resulta fundamental. Con respecto a la primera consagración, señala Paradiso:

Avec l'aspersion des $\kappa \alpha \tau \alpha \chi v ́ \sigma \mu \alpha \tau \alpha$, on célèbre l'agrégation rituelle de Ploutos à la

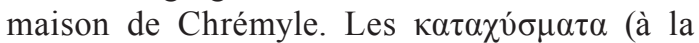
lettre «ce qui est répandu dessus») étaient des poignées de noisettes, dattes, noix, figues sèches et autres fruits secs qu'on répandait sur la tête de la mariée le jour où elle entrait pour la première fois dans la maison de son époux. Le rite était célébré auprès du foyer, où la mariée était peut-être assise dans la position accroupie du suppliant. (Paradiso, 1987: 256).

Con la aspersión de los $\kappa \alpha \tau \alpha \chi v ́ \sigma \mu \alpha \tau \alpha$, se celebra la agregación ritual de Pluto a la casa de Crémilo. Los $\kappa \alpha \tau \alpha \chi v ́ \sigma \mu \alpha \tau \alpha$ (literalmente "lo que es esparcido encima") eran puñados de avellanas, dátiles, nueces, higos secos y otras frutas secas que se esparcían sobre la cabeza de la desposada el día en que entraba por primera vez en la casa de su esposo. El rito se celebraba junto al hogar, donde la desposada estaba, quizás, en la posición acurrucada del suplicante. (Traducción del autor).

Luego tienen lugar los reclamos, que se plantean por parejas de personajes. Los primeros en aparecer son el justo y el sicofanta: el justo

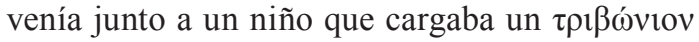
(842, sayo) harapiento, que de forma paródica se asocia con los Grandes Misterios, las festividades religiosas de Deméter, en las cuales se debía lucir vestidos blancos e impolutos, y en las cuales se asistía a la revelación de verdades ocultas, de modo que se sugiere, una vez más, este eje semiótico; por su parte, el sicofanta es despojado de su Goínó $\tau$ iov (926, vestido) lujoso y obligado a

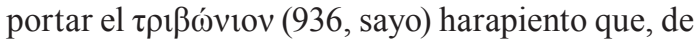
acuerdo con el nuevo orden, le vienen más a tono.

Los segundos en hacer su entrada, en medio de la danza del coro, son la vieja y

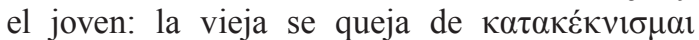
(973, sufrir comezón), con lo cual se remite al elemento sexual característico de la inversión carnavalesca, y si antes el joven se la quitaba a cambio de riquezas, ya en el nuevo orden no las necesita. Según la didascalia, el joven viene con coronas y con una antorcha, otro componente del ritual en torno a los misterios de Eleusis, puesto que, en el texto cultural de Deméter y Perséfone, la madre busca a su hija con antorchas en la oscuridad, del mismo modo que los iniciados deben alumbrar los secretos ocultos.

Siempre en torno al coro danzante, ingresa a escena la tercera pareja, Hermes y el sacerdote de Zeus: Hermes, el mensajero, anuncia las consecuencias del nuevo orden entre los dioses, ya nadie les $\theta$ v́єı (1116, ofrece en sacrificio), por lo cual, con el cambio del infortunio a la fortuna en la Tierra, se operó, en el Olimpo, el movimiento inverso. Si Zeus era injusto con los hombres para beneficio de los dioses, la nueva justicia entre aquellos no consigue sino perjudicar a estos. En este sentido, la argumentación de Penia prevenía sobre la necesidad de la pobreza para mantener el orden establecido, a la vez que sobre el potencial de la riqueza para alcanzar una autoridad alternativa.

Tras la inversión no son los hombres quienes deben servir a los dioses, ni los esclavos quienes deben servir a los amos, sino los dioses quienes hacen las veces de esclavos. Hermes ofrece sus servicios en casa de Crémilo según sus atributos divinos, pero con casi todos es rechazado. Así, si los justos son ricos, no se

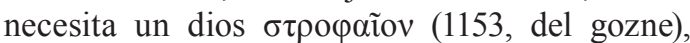
que vigile la entrada de los ladrones; ni uno $\dot{\varepsilon} \mu \pi \mathrm{\alpha} \alpha \alpha \tilde{i} \mathrm{ov}$ (1155, de los comerciantes), que

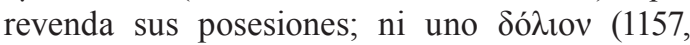
engañoso), porque ahora les va mejor a los

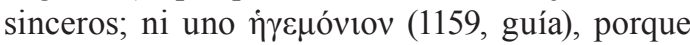
ya Pluto ha recuperado su vista; lo que sí sería útil es un dios Évayóvios (1161, del certamen),

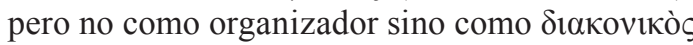
(1170, servidor). Hermes el servidor de Zeus pasa, de este modo, a ser servidor de Crémilo, y hasta de Carión.

Finalmente, el sacerdote de Zeus se encuentra también en apuros con el cambio de poderes. Si no se necesitan los sacrificios para conseguir efectos favorables, porque ya todos los justos han sido beneficiados, entonces alguien que se consagra a Zeus salvador, se ve perjudicado. Igualmente, el daño se invierte: antes, Zeus salvador había dañado a Pluto y, por tanto, a los hombres buenos; ahora, el paródico 
Pluto salvador, como una suerte de Prometeo, ha dañado a Zeus y a los malos, y se encuentra

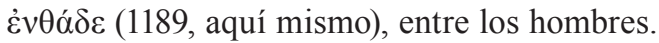

La obra concluye con una segunda consagración de Pluto, esta vez en el templo de Atenea. El texto cultural se refiere al nacimiento de esta diosa, surgida de la cabeza de Zeus, para evitar el cumplimiento de la profecía que proclamaba al hijo nacido de él como su sucesor en el trono olímpico, de la misma manera que él había suplantado a Cronos, y este a Urano. El ritual se acompaña de una procesión, en la que la vieja, como coronada, porta las marmitas de Pluto غ̇лì $\tau \tilde{\eta} \varsigma \kappa \varepsilon \varphi \alpha \lambda \tilde{\eta} \varsigma$ (1198, en la cabeza), y lleva vestidos $\pi$ oıкí $\lambda \alpha$ (1199, bordados), como los que caracterizan a las canéforas. La escena final retoma e invierte la inicial: ya no es el esclavo sino la vieja quien está a la cabeza de la procesión; ya no es Zeus sino Pluto quien se encuentra a la cabeza de los dioses; la corona ya no es un laurel sino una marmita; los vestidos no son ya harapos sino prendas decoradas; y la situación ya no es de pobreza sino de riqueza. El motivo, que queda sugerido, de la unión de la vieja y el joven representa, asimismo, una inversión paródica de la unión cósmica del Cielo y la Tierra, y constituye un cierre bastante apropiado para el nuevo orden, creado a partir de lo cómico y lo carnavalesco. En relación con lo carnavalesco en Aristófanes, escriben Konstan y Dillon:

From another point of view, the grotesque and bawdy humor is just the manifestation of that early exuberance that is natural to festive comedy. What Mikhail Bakhtin identified as the essential features of Rabelaisian humor the holiday inversion of social hierarchy; the valorization of the body and its nether functions; the abandonment of the classical moment, the poised perfection of youth, for processes of birth and decay; fecundity amplified to the absurd degree of pregnant old hags, closing the circle of death and procreation- these features are the heart and soul of Aristophanic laughter. (Konstan \& Dillon, 1981: 381-382).

Desde otro punto de vista, el humor grotesco y obsceno es solo la manifestación de aquella temprana exuberancia que es connatural a la comedia festiva. Lo que Mijaíl Bajtín identificó como los aspectos esenciales del humor rabelesiano -la inversión festiva de la jerarquía social; la valorización del cuerpo y sus funciones inferiores; el abandono del momento clásico, la perfección suspendida de la juventud, los procesos de nacimiento y decadencia; la fecundidad amplificada al grado absurdo de las viejas embarazadas, cerrando el círculo de la muerte y la procreación- estos aspectos constituyen la esencia de la risa aristofánica. (Traducción del autor).

Los ejes semióticos también han sido invertidos. Por una parte, la autoridad de Zeus, fijada en el texto cultural de la mitología en torno a las luchas por la sucesión entre los dioses, ha cedido el paso a una nueva autoridad, la de Pluto, que es más justa. En este sentido, juega un papel de primer orden la figura del esclavo: Carión, coronado al inicio de la obra, conduce a la restitución de Pluto, coronado al final de la obra; de la subversión se pasa a la autoridad. Por otra parte, la revelación de este nuevo orden se sugiere por medio de indicios distribuidos a lo largo de la semiótica textual, los cuales remiten bien a textos culturales bien a intertextos ordinarios, y el efecto se consigue mediante la inversión característica del carnaval. Así, de la ocultación inicial, asociada con los misterios del oráculo de Delfos, se pasa a una revelación, señalada en la curación de la ceguera en el templo de Asclepio, en la alusión a los misterios en las fiestas de Deméter.

\section{Conclusiones}

A partir del análisis de los indicios textuales, con respecto al eje semiótico invertido subversión/autoridad, se ha encontrado la relevancia de la lexía $\kappa \varepsilon \varphi \alpha \lambda \eta ́$, en sus once apariciones, para el establecimiento del nuevo orden de Pluto. Esta lectura ha posibilitado la valoración del Pluto como tratamiento paródico y carnavalesco del texto cultural de las luchas de sucesión entre los dioses. Lejos de contradecir los estudios sobre la influencia del contexto histórico 
en la comedia, se enriquece esta perspectiva: a fin de cuentas, el nuevo orden de la riqueza, que de alguna manera destrona al antiguo sistema de creencias, es lo que vive la Atenas de finales del siglo V a.C. y principios del siglo IV a.C.

Con esta lectura, se contribuye al análisis de las obras de Aristófanes en tres aspectos fundamentales: ejemplificación de la inversión carnavalesca como modalidad de lo cómico en la última de sus obras; demostración de la parodia, no solo histórica, sino también de los textos culturales de Zeus, de Apolo y de Deméter, así como del intertexto ordinario de La Odisea; y propuesta de una posible explicación para el agón, tan problemático desde el punto de vista argumentativo.

Los indicios textuales han servido como base desde dos perspectivas: la onomástica y las lexías. El significado etimológico de los nombres ha permitido su clasificación, en el nivel denotativo, en dos grupos: riqueza (Pluto, Crémilo, Carión) y pobreza (Penia). Los indicios de las lexías han funcionado en tres aspectos. En primer lugar, la estructura dramática: el prólogo de Carión, el agón de Crémilo y Penia, y la procesión del nuevo dios a la cabeza; todos estos momentos de la acción se encuentran repletos de indicios que, también en el nivel denotativo, se refieren, inicialmente, a la pobreza, y a la ceguera, y, posteriormente, a sus opuestos, la riqueza y la visión. Por su parte los ejes semióticos de locura/cordura e injusticia/justicia remiten, respectivamente, a la cabeza como espacio de entendimiento y de asentamiento de la moral.

En segundo lugar, las lexías se manifiestan en la utilería: la corona, al inscribir el texto cultural de Apolo, opera sobre el eje semiótico subversión/autoridad; y los harapos, al parodiar el texto cultural de Deméter, se asocian con el eje semiótico ocultación/revelación. En adición, la corona, por su ubicación en la cabeza, sirve de base para la inversión carnavalesca, en tanto se pasa de la corona de laurel del esclavo, subversión del orden establecido de Zeus, a la marmita que corona a la vieja, signo de la autoridad del nuevo orden de Pluto. Y, en tercer lugar, las lexías permiten la clasificación de los personajes que reclaman en las escenas finales en parejas: el justo y el sicofanta, con el cambio de vestidos; el joven y la vieja, con la nueva corona; y el sacerdote y Hermes, como nuevo servidor. En todos los casos, se da una inversión.

Por último, el eje semiótico principal, subversión/autoridad, se complementa con uno secundario, ocultación/revelación. El primero, a partir de la subversión del esclavo Carión, inscribe el texto cultural de Zeus, el cual, por medio de la relación con los textos culturales de Prometeo, Asclepio y Atenea, sugiere los cambios de poder y la jerarquía de la cabeza. El segundo, orientado hacia la revelación del amo Crémilo, inserta el texto cultural de Apolo, que, complementado por el texto cultural de Deméter, revela la ambigüedad presente en la semiótica textual. Es, precisamente, en dicha ambigüedad, reflejada extraordinariamente en el agón, donde reside la riqueza del Pluto de Aristófanes.

\section{Bibliografía principal}

Aristófanes. 2004. Las Nubes. Las Ranas. Pluto. Edición y traducción de Francisco Rodríguez Adrados y Juan Rodríguez Somolinos. Madrid, España: Cátedra.

Aristophanes. 1907. Comoediae. Edited by F. W. Hall and W. M. Geldart. II Vol. Oxford, United Kingdom: Clarendon Press. Available at www.perseus.tufts.edu.

\section{Secundaria}

Arnott, Geoffrey. 1972. "From Aristophanes to Menander". In Greece \& Rome XIX (1): 65-80. Retrieved from JSTOR database.

Bailly, Anatole. 2000. Dictionnaire GrecFrançais. Paris, France: Hachette.

Beristáin, Helena. 1997. Diccionario de retórica y poética. México D. F., México: Porrúa. 
Chantraîne, Pierre. 1968. Dictionnaire étymologique de la langue grecque. II Vol. Paris, France: Éditions Klincksieck.

Chevalier, Jean; Gheerbrant, Alain. 2007. Diccionario de los símbolos. Barcelona, España: Herder.

Cros, Edmond. 2002. El sujeto cultural. Sociocrítica y psicoanálisis. Medellín, Colombia: Fondo Editorial Universitario.

Dick, Bernard. 1963. "In the Entertainment World: Aristophanes' Plutus". In The Classical World LVI (8): 265-266. Retrieved from JSTOR database.

Douglas, S. 1989. "Cario and the New World of Aristophanes' Plutus". In Transactions of the American Philological Association CXIX: 193-199. Retrieved from JSTOR database.

Douglas, S. 1990. "Economics and Ideology in Aristophanes' Wealth". In Harvard Studies in Classical Philology XCIII: 223242. Retrieved from JSTOR database.

Dover, K. 1972. Aristophanic Comedy. California, United States: University of California Press.

García, Carlos. 2004. Introducción a la mitología griega. Madrid, España: Alianza.

García, Manuela. 1996. "Algunas consideraciones sobre Pluto de Aristófanes y Timón o el Misántropo de Luciano". En Archivum XLVI-XLVII: 191-209.

Gil, Luis. 1993. "La comicidad en Aristófanes". En Cuadernos de Filología Clásica III: 23-39.

Groton, Anne. 1990. "Wreaths and Rags in Aristophanes' 'Plutus". In The Classical Journal LXXXVI (1): 16-22. Retrieved from JSTOR database.
Howatson, M. C. 1991. Diccionario de la literatura clásica. Madrid, España: Alianza.

Konstan, David \& Matthew Dillon. 1981. "The Ideology of Aristophanes' Wealth". In The American Journal of Philology CII (4): 371-394. Retrieved from JSTOR database.

Lasso, José. 1972. "Realidad, idealidad y política en la comedia de Aristófanes". En Cuadernos de Filología Clásica V: 9-90.

McGlew, James. 1997. "After Irony: Aristophanes' Wealth and Its Modern Interpreters". In The American Journal of Philology CXVIII (1): 35-53. Retrieved from JSTOR database.

Pabón, José. 1999. Diccionario Manual GriegoEspañol. Barcelona, España: Vox.

Paradiso, Annalisa. 1987. "Le rite de passage du Ploutos d'Aristophane". En Metis, II (2): 249-267.

Sardón, Isabel. 1996. "Formas del Carnaval en el Teatro. Del "realismo grotesco" de Aristófanes, a los "criados" de la comedia de Menandro". En Castilla: Estudios de Literatura XXI: 195-212.

Watkins, Calvert. 2000. The American Heritage Dictionary of Indo-European Roots. Boston, Massachusetts: Houghton Mifflin Company.

Zumbrunnen, John. 2006. "Fantasy, Irony and Economic Justice in Aristophanes' Assemblywomen and Wealth". In The American Political Science Review C (3): 319-333. Retrieved from JSTOR database. 
